\section{IMPRESSION PROBLEMS SOLVED}

GC Europe has harnessed the best qualities of two great materials to form the next generation impression material: Vinyl PolyEther Silicone (VPES).

With EXA'lence GC solves a number of common problems related to impression taking. With distinctively predictable impressions under all conditions, EXA'lence represents the next generation impression material.

EXA'lence possesses high elasticity and tear strength, combined with constant hydrophilicity and exceptional flow - the result being one of the most accurate impressions obtainable in the market today. EXA'lence is predictable in an unpredictable environment

\section{REPARATIVE TOOTHPASTE}

Those attending the 2011 British Dental Conference and Exhibition can catch a glimpse of new Sensodyne Repair \& Protect, a daily fluoride toothpaste containing advanced

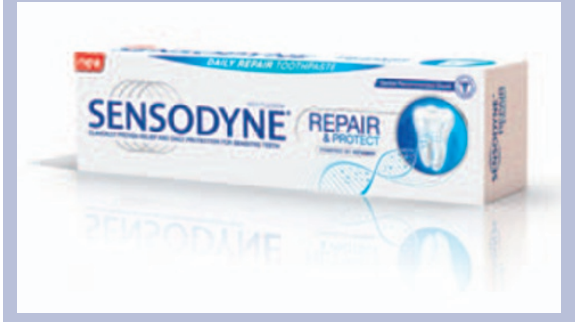

and virtually eliminates the need for retakes. EXA'lence provides an incredible level of detail that is paramount for optimal-fitting restorations. Every aspect of EXA'lence's unique chemistry is designed to make it the ideal material for every dentist and technicians on the path to clinical excellence.

EXA'lence offers you: intrinsic hydrophilicity to capture the finest details, even in a moist environment; outstanding flow and thixotropic characteristics to capture all details and clear crisp margins; superior elasticity with a high degree of toughness to resist tearing; a pleasant mint taste; and a wide choice of setting times and viscosities.

Reader response number 53

NovaMin technology which delivers clinically proven relief from dentine hypersensitivity.

Sensodyne Repair \&t Protect builds a substantive reparative layer over exposed dentine using the natural building blocks of teeth. Visitors to the GSK stand can learn more about the science underpinning NovaMin technology. The GSK team will also be on stand C41-48 throughout the exhibition to provide information on other oral care brands including Corsodyl, Sensodyne Pronamel, Aquafresh, Poligrip and Biotène. Reader response number 54

\section{A NATURALLY AESTHETIC SMILE}

Coltène Whaledent is proud to present a new and easy system for restoring anterior teeth. With COMPONEER the polymerised, prefabricated nanohybrid composite enamel shells combine the advantages of direct composite and prefabricated veneers.

In present practice the choice is between a directly modelled composite restoration or elaborate indirect veneer technology but now the COMPONEER system offers you another treatment option with the advantage of a lower economic perspective to the practitioner and the patient. A naturally aesthetic smile can be offered to the patient in just one session with this easy to use system which also allows for a high level of hard tooth conservation and has a wide range of uses in aesthetic and clinical applications.

Reader response number 56

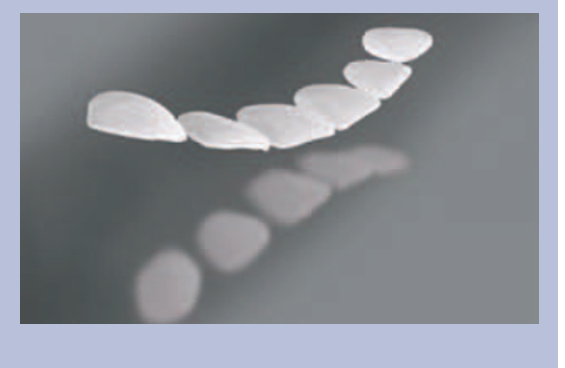

\section{SUPPLIES WITH A SMILE}

National Smile Month takes place from 15 May-15 June 2011. Whatever events you have planned for your patients, The Dental Directory can help. As the UK's largest dental supplier, The Dental Directory offers one of the most comprehensive ranges of oral hygiene products available - all ready for free next day delivery, and all at low prices.

To celebrate Smile Month The Dental Directory have some great offers on products from Molar, TePe, Colgate, Oral-B, Wisdom, GSK, Waterpik, Dentocare, Philips and many more. A good selection of children's oral hygiene products, the latest motivator stickers and motivator products are also available.

Reader response number 57 